Revue

Revue de l'histoire des religions

de Ihistoire des religions

3 | 2016

Varia

Bernard ForTHOMme, La Pensée franciscaine. Un seuil de la modernité

Paris, Les Belles Lettres (« L'âne d'or »), 2014

Antoine Calvet

CpenEdition

Journals

Édition électronique

URL : http://journals.openedition.org/rhr/8608

DOI : 10.4000/rhr.8608

ISSN : 2105-2573

Éditeur

Armand Colin

Édition imprimée

Date de publication : 1 septembre 2016

Pagination : 447-449

ISBN : $978-2-200-93061-5$

ISSN : 0035-1423

Référence électronique

Antoine Calvet, "Bernard Forтномме, La Pensée franciscaine. Un seuil de la modernité », Revue de l'histoire des religions [En ligne], 3 | 2016, mis en ligne le 06 octobre 2016, consulté le 23 septembre 2020. URL : http://journals.openedition.org/rhr/8608; DOI : https://doi.org/10.4000/rhr.8608

Ce document a été généré automatiquement le 23 septembre 2020

Tous droits réservés 


\title{
Bernard FORTHOMME, La Pensée franciscaine. Un seuil de la modernité
}

\author{
Paris, Les Belles Lettres (« L’âne d'or »), 2014
}

\author{
Antoine Calvet
}

\section{RÉFÉRENCE}

Bernard FORTHOMME, La Pensée franciscaine. Un seuil de la modernité, Paris, Les Belles Lettres («L'âne d'or »), 2014, 21,5 cm, 462 p., $35 €$ € ISBN 978-2-251-42052-3.

Depuis longtemps déjà, des personnalités aussi illustres qu'Albert le Grand, Thomas d'Aquin, Maître Eckhart ont définitivement inscrit dans la mémoire collective l'idée que la pensée au Moyen Âge se réduisait essentiellement aux intellectuels de l'ordre mendiant fondé par le prédicateur Domingo de Guzmán (saint Dominique, ca 1170-1221). D'où l'immense intérêt du livre de B. F., lequel, dans le sillage de travaux récents d'Alain Boureau, de Jacques Dalarun, de Giacomo Todeschini ou de Sylvain Piron, essaie de montrer en quoi la pensée franciscaine amorce le saut dans l'ère moderne de manière plus nette, peut-être, que l'école dominicaine. Son projet initial le conduit à regrouper sous la bannière de l'ordre mineur des idées et des concepts d'une grande diversité, et c'est à ses yeux cette diversité qui caractérise la famille franciscaine. L'auteur évoque une «convergence apostolique» des quatre grands docteurs franciscains symbolisée par les quatre évangélistes, comme on peut le voir sur la page de titre gravée des Rerum Metaphysicarum libri tres. Ad mentem Doctoris Subtilis (Paris, 1623) du frère Martin Meurisse : «Marc (Ockham), l'évangéliste le plus critique ; Matthieu (Bonaventure), l'évangéliste le plus ecclésial; Luc (Alexandre de Halès), l'évangéliste sapientiel de la métanoïa; et Jean (Duns Scot), l'évangéliste le plus métahistorique » (p. 31).

2 Tout au long de son livre, B. F. s'efforce de synthétiser une pensée certes inscrite dans un contexte médiéval, mais dont la conception de la rationalité participerait de l'émergence de la modernité. Son discours s'articule autour des deux figures notables 
du franciscanisme intellectuel, Jean Duns Scot (ca 1265-1308) et Guillaume d'Ockham (ca 1300-ca 1350); le premier en tant que penseur de la liberté, le second en tant qu'il renouvelle les rapports entre l'être et le langage. Si ce dernier annonce la philosophie analytique, et si, à ce titre, il continue d'irriguer les spéculations les plus hardies sur le langage, Duns Scot, lui, reste pour beaucoup de nos contemporains un philosophe assez obscur, en France tout au moins, et cela en dépit des travaux et des traductions d'Olivier Boulnois qui a labouré en profondeur cette terre rarement explorée (voir son dernier ouvrage, Lire le Principe d'individuation de Duns Scot, Paris, Vrin, 2014). Des notions éminemment scotistes telles que «contingence ", "liberté » et surtout "volonté ou volition » auraient demandé de plus amples explications, d'autant que le train de la philosophie moderne (Descartes, Spinoza) et, plus particulièrement, celui de la philosophie allemande (Kant, Hegel, Nietszche) en ont changé l'énoncé et approfondi la portée depuis l'époque scolastique. Sur le plan des définitions et des éclaircissements attendus, B. F. laisse trop souvent notre soif de comprendre inassouvie. Rappelons que Duns Scot fait de la volition un concept central de sa réflexion. Prenant le contre-pied de Thomas d'Aquin, il la définit comme «causa subserviens » de l'Intellect, de sorte que, comme l'explique dans des pages lumineuses Hannah Arendt (La Vie de l'Esprit, t. 2, Le Vouloir, Paris, 1983, p. 147-171), dans l'optique du Docteur subtil, l'Intellect devient simple faculté servante de la volonté. Arendt jugeait cette philosophie de la liberté intrinsèquement liée à la capacité humaine de vouloir ou de ne pas vouloir comme la plus audacieuse et la plus inventive avant celle de Kant.

3 Le plan de B. F. revient donc à suivre le fil directeur de ces idées associées aux noms des deux phares de la pensée franciscaine. Volonté, liberté, logique, ontologie, vie, anthropologie, jouissance intellectuelle sont les charnières de son exposé. Cependant, selon l'auteur, on ne peut saisir l'ampleur et la vérité de la pensée franciscaine que si l'on part de la Règle écrite par le fondateur de l'ordre : « la pensée franciscaine, c'est la compréhension de la règle » (p. 32). Voilà le dénominateur commun, que l'on prenne en compte la nature, ou le royaume des idées et celui des axiomes mathématiques. En tant qu'il est un "homo novus ", appelant ses frères à vivre selon l'évangile, c'est-à-dire, insiste B. F., à vivre en faisant un « usage simple » de la vie, un usage simple et joyeux de la vie, saint François ouvre toutes grandes les portes d'une nouvelle perception des choses et des êtres. «La pensée spirituelle de François, c'est la Règle comme forme de vie des frères mineurs reçue librement: la sienne et celle de ses frères » (p. 31). La Règle, c'est la substance de la pensée franciscaine; s'en détacher, c'est affaiblir cette pensée ; s'y attacher, c'est projeter l'ordre mineur dans le monde, au-delà des frontières du christianisme; c'est faire de l'Évangile un évangile-monde, comme le théorise la théologie de la libération.

4 Nous atteignons ici la limite de l'exercice auquel se livre B. F., lui-même frère mineur. Il court dans tout son livre une veine apologétique qui en compromet l'équilibre. Ses engagements, sa foi l'emportent vers des sommets et un lecteur plus circonspect a du mal à le suivre dans tous ses cheminements. Pour ne prendre qu'un exemple de cette tendance générale, ramener Rabelais à son état de franciscain - ce qu'indéniablement il fut quelque temps - alors que d'aucuns voient son œuvre plutôt comme une des premières manifestations de la libre-pensée, a un je-ne-sais-quoi de gênant et de polémique. Certes, jeune encore, Rabelais s'est formé au grec chez les Cordeliers ; mais il ne resta guère dans l'ordre mineur, obtenant en 1524 d'un indult pontifical l'autorisation de passer des Franciscains aux Bénédictins de Maillezais ; plus tard, c'est en habit de prêtre séculier qu'il étudia la médecine et prit ses premiers grades. De le 
citer comme frère mineur (p. 76-78, p. 113) nous paraît dès lors une sorte d'extrapolation tout à fait contestable. Plus préoccupant encore est le quasi-silence de B. F. sur le sujet du prophétisme et de l'eschatologie de lignée joachimite, fortement représentée chez les Franciscains de la fin du Moyen Âge (cf. Marjorie Reeves, The Influence of Prophecy in the Latter Middle Ages, A Study of Joachimism, Londres - Notre Dame, University of Notre Dame Press, 1993). D'autre part, en concentrant sa recherche sur Duns Scot et Ockham, B.F. élude quelque peu la querelle de la Pauvreté, ne mentionnant Pierre de Jean Olivi (1248/1249-1298) que dans le cadre de sa relation intellectuelle avec le Docteur subtil et le Docteur invincible (cf.l'index nominum, plus de trente-quatre citations). Enfin, puisqu'Ockham est l'objet de longues digressions, peut-on vraiment parler de «bévue " philosophique à propos de ces penseurs profanes qui écartent de leur réflexion son rapport à Dieu? N'est-il pas logique et plutôt bienvenu qu'en bonne philosophie, on s'arrête là où commence la mystique?

Les critiques que soulève ce livre et l'agacement suscité par ses partis pris ne doivent pas masquer la somme de travail accompli, que révèle la partie consacrée aux notes : abandonnant le ton de prêcheur qui ponctue plusieurs de ses envolées, F. B. s'y montre un érudit souvent précis et bien renseigné. L'ouvrage s'achève par une chronologie intellectuelle (p. 323-435) qui, de 1215 à 2014, marque les étapes de l'activité spirituelle des frères et des sœurs de l'ordre mineur. Toutefois, pour une approche historique du franciscanisme, qu'il nous soit permis de préférer des travaux moins entachés d'a priori. 